\title{
IMPACT OF THE "COMUNICAT" METHODOLOGY ON THE IMPROVEMENT OF THE "EFFECTIVE ORAL COMMUNICATION" STUDENT OUTCOME OF THE STUDENTS OF THE MASTER IN FOOD SAFETY AND QUALITY MANAGEMENT
}

\author{
Édgar Pérez-Esteve ${ }^{1}$, Joan Albert Silvestre-Cerdà ${ }^{2}$, Maria del Carmen Bas ${ }^{2}$, \\ María Jesús Lerma-García ${ }^{3}$, Nuria Matarredona-Desantes ${ }^{4}$, Raúl Oltra Badenes ${ }^{5}$ \\ ${ }^{1}$ Departament de Tecnologia d'Aliments. Universitat Politècnica de València (SPAIN) \\ ${ }^{2}$ Dep. de Matemàtiques per a l'Economia i l'Empresa, Universitat de València (SPAIN) \\ ${ }^{3}$ Departament de Química Analítica, Universitat de València (SPAIN) \\ ${ }^{4}$ Departament de Composició Arquitectònica, Universitat Politècnica de València (SPAIN) \\ ${ }^{5}$ Departament d'Organizació d'Empreses, Universitat Politècnica de València (SPAIN)
}

\begin{abstract}
During academic course 2017-2018 the Comunica't methodology was created to help students to selflearn all the skills needed to master the areas of domain of the general student outcome "effective oral communication". After two academic years of implementation, the goal of this work is to analyse the degree of contribution of this methodology to development of the "Effective Oral Communication" students' outcome of students that followed the methodology during the subject Audits of Food Safety and Quality Systems, belonging to the Master in Food Safety and Quality Management. To this end, at the beginning of the subject, students were asked to present a topic related to the subject and evaluated with respect to the six areas in which the project has defined the development of the outcome following a rubric. Then the methodology was presented, and at the end of the teaching period the procedure was repeated. Finally, marks obtained before and after the learning intervention were compared. Results showed that the methodology contributed in a great extent to improve the ordering of ideas in the presentation, the non-verbal communication and the design of the slides. Therefore, although there are fields where the methodology contributed to a lower percentage, it can be concluded that the methodology is very effective in improving effective oral communication student outcome.
\end{abstract}

Keywords: Oral communication, self-learning, auto-diagnosis.

\section{INTRODUCTION}

"Effective Oral Communication" is one of the student outcomes to which more attention is given within the university studies, both in Bachelor's and Master's degrees. This is because it is one of the most demanded in the workplace, since good communication is essential for the development of any job. Therefore, it is important to develop the outcome at all the learning levels, reason why university syllabuses contemplate it.

In this context, as important as assessing the proficiency level at the end of a certain subject to certify it, it is providing activities to develop it and evaluating how the followed methodology contributes to this development. To reach this goal, the ComunicaT methodology was created in 2017 [1]. This methodology has been developed within a Project of Innovation and Educational Improvement (PIME) at the Polytechnic University of Valencia, and has as its fundamental objective that the student, after performing a self-diagnosis, can improve their effective oral communication through a self-learning itinerary. In this way, the student, starting from his level of initial proficiency in terms of effective oral communication, follows a self-formative itinerary particularized to his specific situation, with the appropriate training activities. The methodology has been designed and developed by teachers of different profiles, degrees and universities.

The main objective of the Comunica't methodology is to create and provide the students different tools: a) a self-diagnostic tool that allows them to be conscious of their mastery level of the aforementioned competence and $b$ ) an guided self-learning itinerary composed by different training activities adapted to the result obtained in the self-diagnosis tool. 
Throughout the project, different actions have been carried out: a) design of a self-assessment test of the student's effective communication result [2] b) development of self-learning itinerary based on the initial level of proficiency [3] and c) evaluation of the impact of the methodology in different groups of students from the Universitat Politècnica de València and Universitat de València (Spain) $[4,5]$.

In a first experience, the methodology was tested with first year students of the architecture degree (level of proficiency I) [4]. The results of this first experience have revealed that the proposed methodology does not require much class time, since it is an autonomous learning on the part of the student, but at the same time supervised by the teacher to fulfill a learning contract established by both parties. They have also stated that the students significantly improved their proficiency level.

The objective of this second pilot test is to evaluate the efficiency of the Comunica't methodology with a group of students of the subject Systems Audits of Quality Management and Food Safety, belonging to the Master in Quality Management and Food Safety of the Universitat Politècnica de València, and therefore belonging to the level of proficiency III (Master).

\section{METHODOLOGY}

\subsection{Description and the context of the subject: "Audits of food quality"}

The subject "Audits of food quality" belong to the Master of Food Safety and Quality Management offered by the Polythechnic University of Valencia. The subject aims to design audit plans to assess quality and food safety, as well as develop the basic competencies of an auditor. In the 2017-2018 academic year the subject was studied by 32 students, of which 30 participated in this experience.

\subsection{Application of the Comunica't methodology}

The Comunica't methodology was applied to this study in the following way. First of all, students were asked to prepare a brief presentation of a topic related to quality management systems (ISO standards). During the presentation, the students were evaluated as much as their classmates, as well as by the teachers, with the help of a digital rubric placed on a web server. After the presentations, the teachers collected the scores and all the comments from the classmates and prepared an individual report for each of the students. The rubric covered different areas: a) domain of the topic, b) organization of the contents, c) adequacy of the language (verbal communication), d) non-verbal communication, e) presentation tools (design, use of font size, colors, images... in the slides) and f) capacity to answer a question. All the 6 areas could be marked with 4 possibilities: A (excellent), B (good), C (acceptable) and D (criterion not reached).

Secondly, the students were invited to take a self-assessment test to reflect on their weak and strong points in the preparation and execution of the oral presentation [2]. Based on the score in each of the sections of the self-assessment test, students were recommended to work on specific activities to improve their weaknesses [3]. At the end of the course, students were asked to prepare a new presentation. Again, students and teachers evaluated the presentation of each student using the same rubric.

The methodology is summarized in figure 1 . 


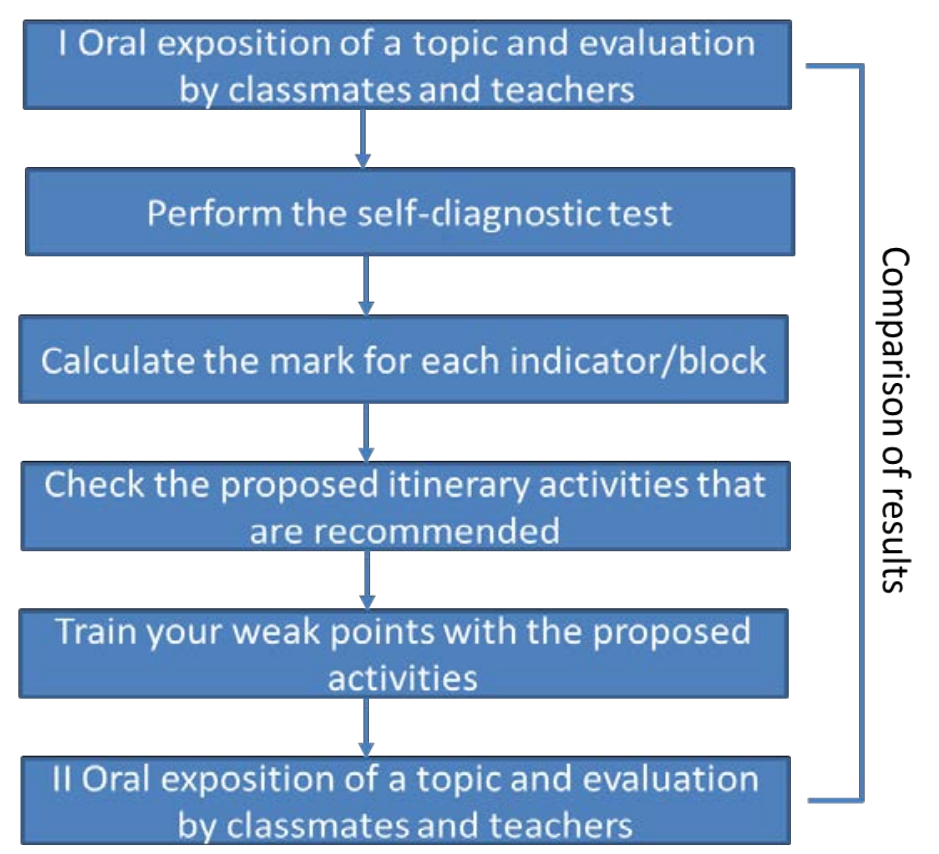

Figure. 1 Diagram of the proposed methodology.

\subsection{Assessment of student improvement}

To evaluate the efficiency of the proposed methodology, a comparison of the marks obtained after exposure I and II by the students and the teachers was carried out.

\section{RESULTS}

\subsection{Level of proficiency before the intervention}

Figure 2 shows the percentages of students who obtained the four possible grades -A (excellent), B (very good), C (acceptable) or D (criterion not reached)- in each of the items evaluated: domain content organization, verbal language, nonverbal language, presentation tools (basically power point) and the development of answers to questions from teachers, before the intervention with the Comunica't project.

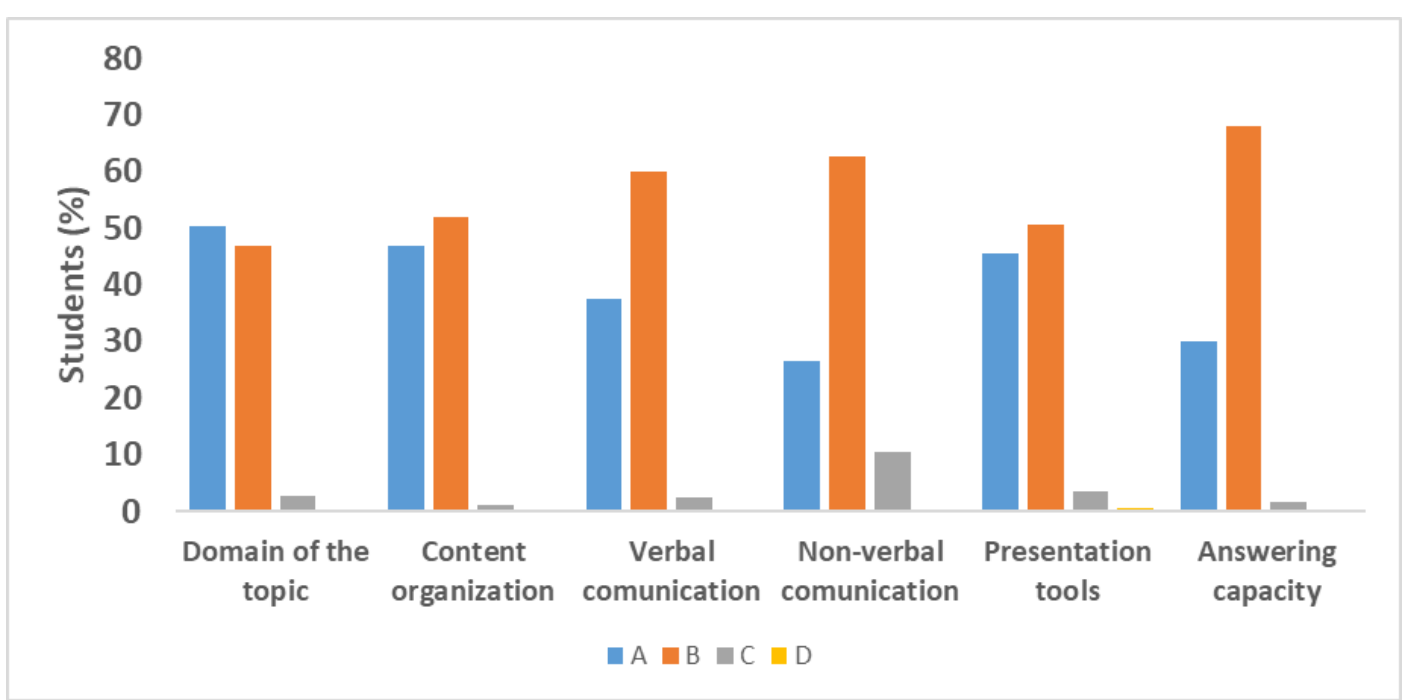

Figure 2. Score obtained by students in the different areas of domain of the general student outcome effective oral communication before the Comunica't methodology, expressed as a percentage of students qualified with the letters $A-D$. 
In the figure it is observed that the students presented a good mastery of the subject, surpassing the students with $A$ the percentage of students with $B, C$ and $D$. The second area of domain where the students were more competent was the use of means of support, but this time the percentage of students with B score was the predominant. The main flaws in this area were the use of very ornate templates that do not highlight the main ideas, the use of unnecessary animations and transitions, the use of very small font sizes and the abuse of the text. Verbal communication was the third area in order of domain. The worst results were obtained in verbal communication ( $30 \%$ of students with $A)$, answer to questions $(29.9 \%$ of students with $A)$ and non-verbal communication ( $26.6 \%$ of students with A). In these cases, the most common errors were to use a generic vocabulary not specific to the area of knowledge, to respond to different aspects to those that were asked, the static position and the excessive use of tags.

\subsection{Level of proficiency after the intervention}

After the first exposition, teachers prosed the students to follow the Comunica't methodology. Then, a second exposition was done by the students. Figure 3 shows the percentages of students who obtained the four possible grades -A (excellent), B (very good), C (acceptable) or D (criterion not reached)- in each of the items evaluated: domain content organization, verbal language, nonverbal language, presentation tools (basically power point) and the development of answers to questions from teachers, after the intervention with the Comunica't project.

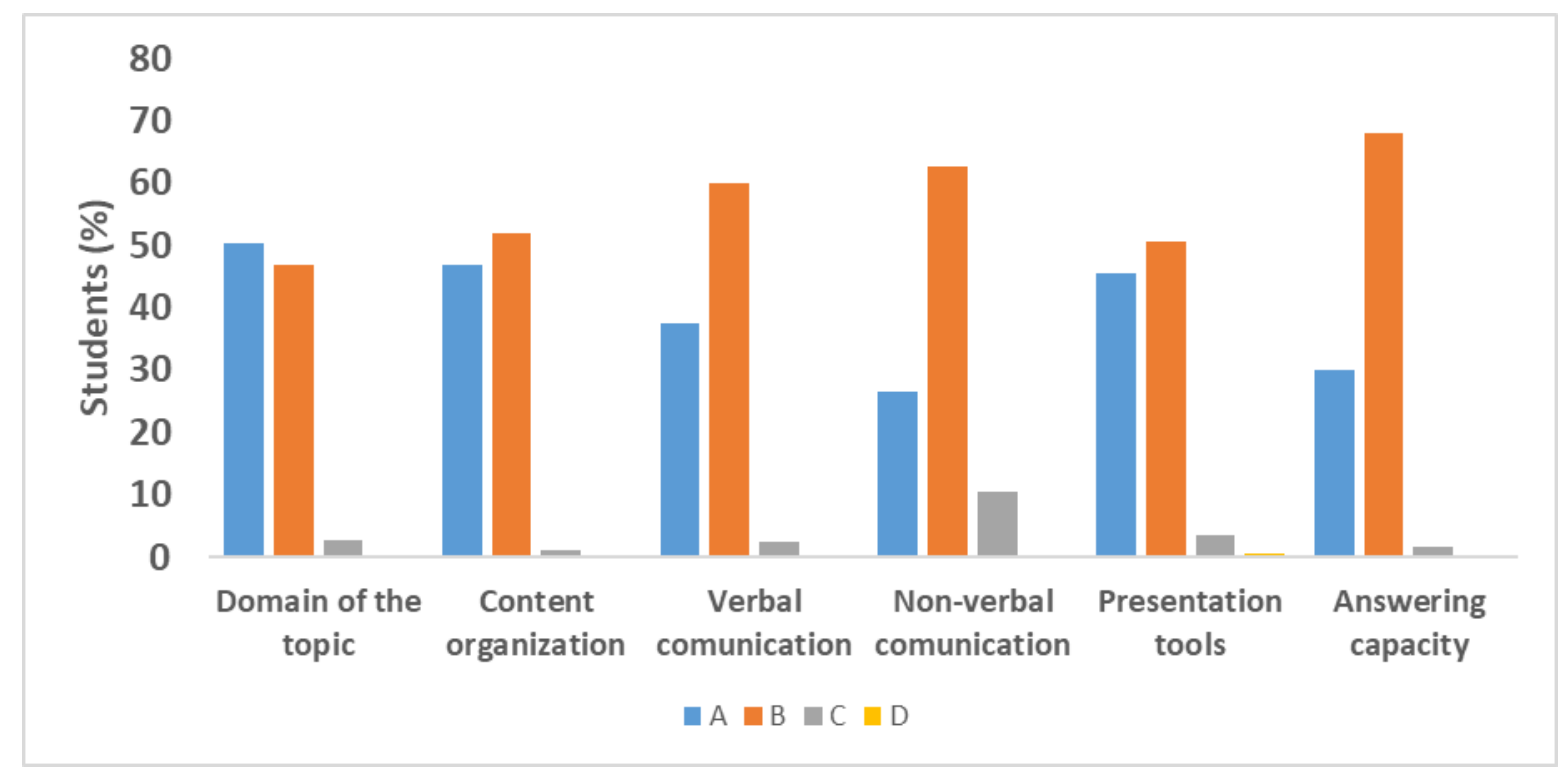

Figure 3. Score obtained by students in the different areas of domain of the general student outcome effective oral communication after the Comunica't methodology, expressed as a percentage of students qualified with the letters $A-D$.

As can be seen in the figure, almost $100 \%$ of the students received a grade of $A$ or $B$ on most of the qualified parameters. It could also be observed how the domain of the subject, the organization of the content and the use of the presentation tool were the areas of competence where the qualifications were higher. In contrast, students received lower grades in non-verbal communication and their ability to respond appropriately to the questions asked.

The comparison of figures 2 and 3 shows that after the proposed intervention the percentage of students with $A$ increased in all the areas of mastery at the same time that the number of students scored with $B$ decreased. On the other side, the grades with $D$ were reduced.

\section{CONCLUSIONS}

According to these results, the methodology has contributed to the development of the effective result of the student's communication. However, there are areas of mastery (i.e. non-verbal communication), in which activities have been less effective in ensuring that more than $30 \%$ of students scored excellent $(A)$. 


\section{ACKNOWLEDGEMENTS}

This work has been developed within the research project called "Implementación de una plataforma cloud para el desarrollo de una metodología autoformativa de la CT "Comunicación Efectiva" y sus procesos de evaluación" (Exp.: PIME/18-19/51) funded by the Vice-Rectorate for Studies, Quality and Acreditation of the Universitat Politècnica de València.

\section{REFERENCES}

[1] R. Oltra-Badenes, E. Pérez-Esteve, J. A. Silvestre-Cerdà, M. C. Bas, M. J. Lerma-García and N. Matarredona-Desantes, "PIMECOE: A project for self-diagnosis of the sudent outcome 'effective communication' and its improvement through a self-formative itinerary". In INTED2018, pp. 38003805, 2018.

[2] M. J. Lerma-García, N. Matarredona-Desantes, R. Oltra-Badenes, E. Pérez-Esteve, J. A. Silvestre-Cerdà, and M. C. Bas, "Development of a self-diagnosis guide to assess the initial proficiency level of the student outcome 'Effective oral communication'", in EDULEARN 2018, pp. 4020-4025, 2018.

[3] E. Pérez-Esteve, J. A. Silvestre-Cerdà, M. C. Bas, M. J. Lerma-García, N. Matarredona-Desantes, and R. Oltra-Badenes, "Activities to promote the self-learning of the effective communication student outcome", in INTED 2018, pp. 3806-3812, 2018.

[4] M. C. Bas, M. J. Lerma-García, N. Matarredona-Desantes, R. Oltra-Badenes, E. Pérez-Esteve, and J. A. Silvestre-Cerdà, "Self learning itinerary as a tool to improve effective communication: a qualitative analysis of a pilot experience", in EDULEARN 2018, pp. 4049-4056, 2018.

[5] J. A. Silvestre-Cerdà, M. C. Bas, M. J. Lerma-García, N. Matarredona-Desantes, R. OltraBadenes, and E. Pérez-Esteve, "Application of a self-learning methodology for the enhancement of the oral communication student outcome in international business studies", in INTED2019, In press. 